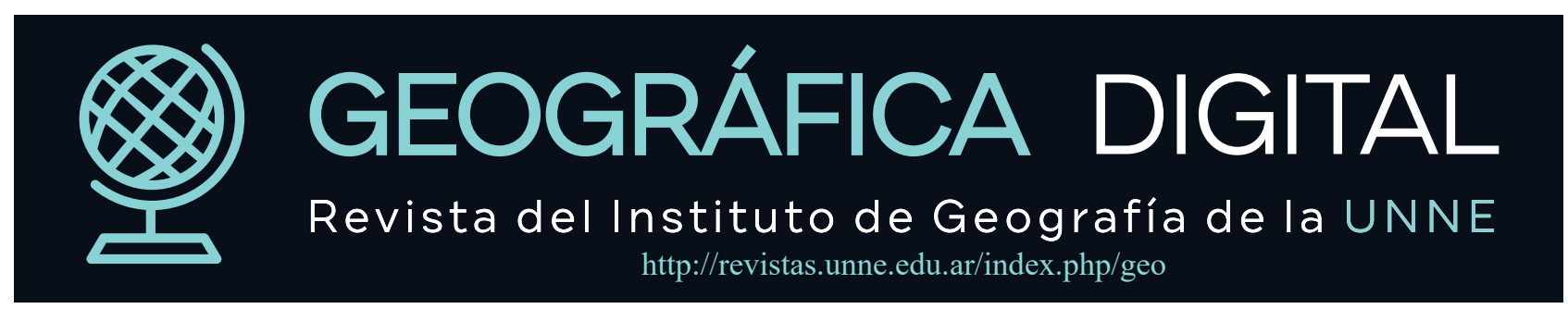

Revista Geográfica Digital, 2019, Vol. 16, No 31, 2-15 pp., E-ISSN: 1668-5180: DOI: https://dx.doi.org/10.30972/geo.16313613

\title{
Presidencia de la Plaza y Machagai. Análisis comparativo del proceso territorial desarrollado en el centro este chaqueño
}

\section{Presidencia de la Plaza and Machagai. Comparative analysis of the territorial process developed in the center east Chaco}

\author{
Cuadra, Dante E. ${ }^{1}$ \\ Martínez, Gerardo R. ${ }^{2}$ \\ ${ }^{1}$ Departamento de Geografía, Facultad de Humanidades de la UNNE. dantecuadra@yahoo.com \\ ${ }^{2}$ Instituto Nacional de Tecnología Agropecuaria (INTA). General San Martín, Chaco. martinez.gerardo@inta.gob.ar
}

Palabras Claves:

Territorio

Medio natural

Poblamiento

Actividades económicas

Organización

político-institucional.

\section{R E S U M E N}

El propósito de esta investigación ha sido analizar y comparar dos espacios vecinos situados en el centro este de la provincia del Chaco. El trabajo desarrollado se centró en la evolución geohistórica, en la conformación político-institucional y en los caracteres naturales, demográficos, económicos y socioculturales de los departamentos de Presidencia de la Plaza y 25 de Mayo. Como resultado de ello, puede decirse que se trata de un espacio que ha sido el ámbito natural de los pueblos originarios qom y moqoit hasta fines del siglo XIX, cuando el ejército argentino emplazó fortines en la zona. Algunos ganaderos provenientes del norte santafesino se instalaron en el área, aprovechando la presencia militar y los trabajos previos al trazado del ferrocarril Central Norte Argentino. El dinamismo demográfico y económico se dio a partir de 1912, cuando los trenes comenzaron a unir Barranqueras con el Km 173 (Presidencia Roque Sáenz Peña), con paradas en los desvíos Km 109 (Presidencia de la Plaza) y Km 129 (Machagai). La explotación forestal fue una actividad importante al iniciarse el proceso, pero entre las décadas de 1920 y 1960 tomó relevancia el cultivo del algodón. En el área rural, tras la crisis de esa actividad agrícola, se expandió la ganadería bovina extensiva y, luego de los años ochenta, las cabeceras departamentales arraigaron a la industria forestal.

\section{A B S T R A C T}

The purpose of this research has been to analyze and compare two neighboring spaces located in the east center of the province of Chaco. The work developed focused on the geohistorical evolution, on the political-institutional conformation and on the natural, demographic, economic and sociocultural characteristics of the departments of the Presidencia de la Plaza and 25 de Mayo. As a result, it can be said that it is a space that has been the natural environment of the original qom and moqoit peoples until the end of the 19th century, when the Argentine army deployed forts in the area. Some farmers from the north of Santa Fe settled in the area, taking advantage of the military presence and the works prior to the Central North Argentine railway. The demographic and economic dynamism began in 1912, when trains began to link Barranqueras with Km 173 (Presidencia RoqueSáenz Peña), with stops at the detours Km 109 (Presidencia de la Plaza) and Km 129 (Machagai). Logging was an important activity at the beginning of the process, but between the 1920s and 1960s, cotton cultivation became important. In the rural area, after the crisis of this agricultural activity, extensive cattle ranching expanded and, after the 1980s, the forest industry took root in departmental capitals. 


\section{Introducción}

Las áreas de estudio han sido elegidas en función de la escasa información específica que, sobre estos espacios locales y sus entornos, contienen los trabajos más genéricos (de escalas provincial y regional) difundidos en el campo de la geohistoria. El aporte de este trabajo apunta, por tanto, a desentrañar los caracteres estructurales y evolutivos de estas áreas, reconociendo los rasgos que son comunes o compartidos en la totalidad del espacio considerado y, además, aquéllos que son propios o distintivos de cada una y que, consiguientemente, hacen a su identidad. Muchos de los datos, descripciones y relaciones referidos a estos espacios locales, que aparecen en el presente artículo, resultan del rescate de relatos, hechos y situaciones que los autores han obtenido en el territorio a lo largo de varios años de trabajo, sobre todo entre 2014 y 2018. Estos aportes se interconectan y contextualizan con datos provenientes de distintas fuentes y autores, a los efectos de una mejor comprensión de los espacios abordados.

La organización del presente trabajo contempla inicialmente los antecedentes que se han encontrado sobre el tema, el marco teórico que contextualiza la investigación y los materiales y métodos que posibilitaron el desarrollo de la misma. Luego, se consignan los resultados, donde se vuelca el desarrollo o cuerpo analítico, el cual se estructura con el siguiente orden temático: breve caracterización del medio natural, el proceso de conformación territorial, los caracteres demográficos y su evolución, constitución de los centros urbanos, la dinámica económica: la explotación forestal y las actividades agropecuarias. Posteriormente se exponen la discusión de los resultados y las conclusiones. Por último, se detallan la bibliografía y las fuentes consultadas.

\section{Antecedentes}

Son muy pocos los trabajos específicos realizados sobre el área de estudio, entre los que figuran los aportes de García y Busiello (de 1997, referido a los orígenes de Presidencia de la Plaza, considerando el período 1910-1940), de Dellamea y Cuadra (de 2015, donde se tratan aspectos geográficos e históricos de Machagai y del departamento 25 de Mayo) y de Martínez (de 2017, que hizo lo propio con el departamento Presidencia de la Plaza). También existen informes técnicos generados en organismos como el INTA y entes gubernamentales de la provincia que, por lo general, tratan aspectos puntuales, en mayor medida vinculados con los sectores productivos. Otros datos se hallan dispersos en diversas publicaciones desarrolladas a escala provincial y regional, con alusiones a hechos o fenómenos correspondientes a este espacio del Chaco centro oriental o como parte de procesos más generales, entre cuyos autores se destacan Miranda (1955), Bruniard (1979), Beck (1994), Maeder (1997) y Manoiloff, (2001 y 2008).

\section{Marco teórico}

El trabajo se ha desarrollado desde el paradigma sociohistórico, específicamente desde la perspectiva de la geografía histórica. La concepción de espacio geográfico (como categoría conceptual aglutinante) es entendida como instancia de la totalidad social (Blanco, 2007), la cual trasciende la mirada unilineal de espacio construido socialmente para incorporar la incidencia que esa construcción tiene sobre el medio (natural, social y cultural), a modo de retroalimentación, admitiendo que ese medio vuelve a influir y transformar a la sociedad, pero de manera diferente. Esta perspectiva teórica admite abordar la espacialidad desde una visión más compleja y dinámica que impregna a las restantes categorías conceptuales aglutinadas, tales como territorio (Foucoult, 2004; Haesbaert, 2004; Blanco, 2007; Bozzano, 2009), paisaje (Sauer, 1925; Dollfus, 1976) y lugar (Massey, 1994; Tuan, 2007).

Por el carácter analógico del trabajo, se han tomado como directrices a cinco principios geográficos: la localización, la comparación, la conexión, la causalidad y la evolución (Daus, 1961; Plans, 1984; Pickenhayn, 1994). Esta visión epistémica fue la guía durante todo el proceso de investigación y la que, en definitiva, posibilitó el diálogo y la integración de saberes entre sujetos cognoscentes y sujetos conocidos (Vasilachis de Gialdino, 2011) y, también, entre los propios investigadores, cuyas formaciones de grado devienen de distintos campos del conocimiento, pero hallaron convergencia en la ciencia geográfica a través de estudios de postgrado.

\section{Materiales y métodos}

El trabajo se ha basado en la recolección de información geohistórica, proveniente de distintas fuentes: Archivo Histórico de la Provincia del Chaco, censos nacionales y territoriales de población, censos 
agropecuarios, organismos gubernamentales, entes privados y publicaciones analógicas de instituciones y autores referentes en el tema. Asimismo, se han realizado numerosas salidas de campo, obteniéndose documentos primarios resultantes de observaciones y entrevistas a actores calificados. El relato de antiguos pobladores y la disponibilidad de fotografías de diferentes épocas, facilitaron la comprensión de hechos y procesos, enriqueciendo el trabajo y otorgándole significación a la trama geohistórica abordada. Además, ha sido de gran utilidad, a los fines de la localización y comparación de los hechos estudiados, la consulta y análisis de diferentes documentos cartográficos e imágenes satelitales del área de estudio.

Una vez determinado el recorte espacial y temporal de la investigación, se obtuvieron los datos e informaciones provenientes de fuentes primarias y secundarias, procediéndose a la sistematización de los mismos y, seguidamente, los análisis, comparaciones y correlaciones (estas últimas, en los casos posibles), etapa en la que también se incorporaron las herramientas estadísticas, documentales, gráficas, cartográficas y remotas en vistas a la comprensión del tema elegido y al cumplimiento de los objetivos trazados. Terminado este proceso, se elaboraron las conclusiones.

Cabe señalar que el conocimiento empírico, de carácter vivencial e investigativo, adquirido por ambos autores a lo largo de muchos años en el área de estudio, posibilitó poner en práctica los principios geográficos, en torno a los cuales se organizó la redacción del presente artículo.

\section{Resultados}

El espacio centro oriental de la actual provincia del Chaco fue, tradicionalmente, un ámbito de asentamientos y sitios de cacerías de los pueblos originarios qom y moqoit. Ello dio origen al topónimo "Machagai", que significa lugar de descanso de los cazadores. (Relatos de O.S. y M.F., habitantes y referentes originarios qom).

A fines del siglo XIX el ejército argentino emplazó fortines en el área, tales los casos de Napalpí, Indio Disparado, Paraje Aguará, El Totoral, Fortín Aguilar y Paso de Oso (Beck, 1994).

Hacendados procedentes del norte santafesino comenzaron a llegar a esta zona antes del término de la primera década del siglo XX, aprovechando la presencia y protección militar y los trabajos de apertura de picadas, nivelación y relleno del terreno y emplazamiento de alcantarillas que técnicos y obreros realizaban, previos al trazado de las vías del ferrocarril Central Norte Argentino (García y Busiello, 1997).

Figura 1. Ubicación del área de estudio

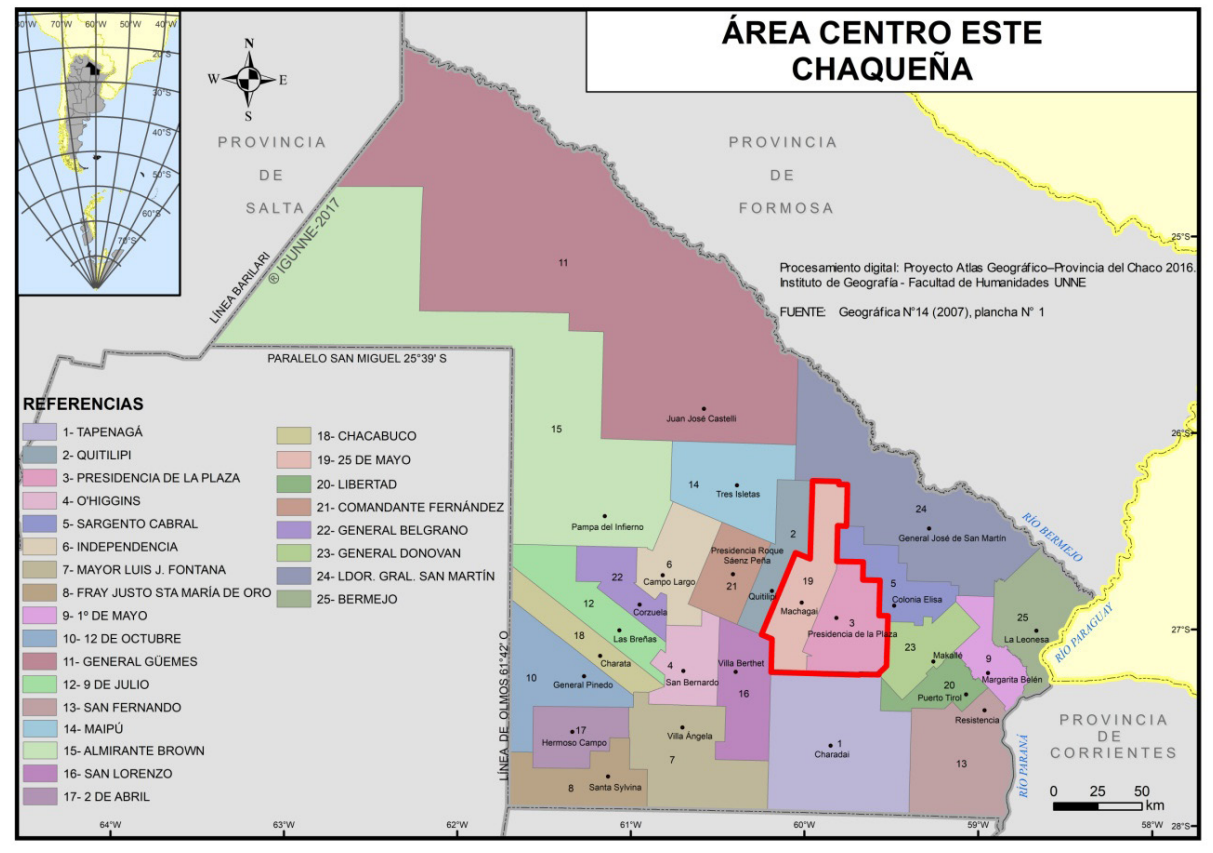

Fuente: Revista Geográfica № 14 (2007). Plancha № 1. IGUNNE.

El dinamismo demográfico y económico se desató a partir de 1912, cuando los trenes comenzaron a unir Barranqueras con el Km 173 (actual Presidencia Roque Sáenz Peña), con paradas en los desvíos Km 109 (hoy Presidencia de la Plaza) y Km 129 (luego conocido con el nombre de Machagai, topónimo recuperado del pueblo qom que ancestralmente asignaba ese nombre al lugar). Esos desvíos, donde se procedía a la carga de rollos y rollizos forestales y a la descarga de mercancías para las incipientes poblaciones generadas 
a su alrededor, se transformaron oficialmente en estaciones ferroviarias con el correr de los años. Por entonces, este medio de comunicación y transporte resultaba esencial, dado que los caminos eran escasos y la transitabilidad dificultosa, sobre todo en épocas de precipitaciones prolongadas (Dellamea y Cuadra, 2015).

La explotación forestal constituyó una actividad de gran importancia en los inicios de este proceso demográfico y económico, ya que las maderas representaban el recurso natural más abundante y accesible. Casas precarias, hacheros, picadas, carruajes, bueyes e implementos de trabajo fueron los elementos distintivos del paisaje, que tenía como puntos de convergencia a los desvíos ferroviarios ubicados a $20 \mathrm{~km}$ entre sí, distancia que necesitaban los trenes de vapor para reabastecerse de agua (Relato de G.G., antiguo poblador).

\subsection{Breve caracterización del medio natural}

El ámbito natural, por tratarse de jurisdicciones contiguas, exhibe una gran similitud entre los dos departamentos considerados, sólo que Presidencia de la Plaza presenta un área baja e inundable más extendida hacia el sur. Asimismo, por localizarse más hacia el oriente, recibe algunas decenas de mm anuales superiores a las de 25 de Mayo (1.150 y $1.100 \mathrm{~mm}$, respectivamente), compartiendo el régimen pluviométrico subtropical Atlántico (Bruniard, 1979).

El área se halla sobre planicies de acumulación, aunque desde el punto de vista topográfico Presidencia de la Plaza se sitúa a menor altitud (predominantemente entre 65 y $78 \mathrm{~m}$ ), en tanto, 25 de Mayo se desarrolla mayormente entre las cotas de 75 y $85 \mathrm{~m}$ (sobre el nivel del mar).

En cuanto a la aptitud de suelos, sólo la mitad norte de Presidencia de la Plaza tiene predominio de la clase III (agricultura con limitaciones o riesgos moderados), mientras que en 25 de Mayo este suelo se extiende en gran parte del departamento; contrariamente, los suelos IV y VI (agricultura con limitaciones o riesgos severos y suelos no aptos para agricultura, respectivamente) ocupan una amplia franja del sur placeño, mientras que en el departamento vecino involucran una superficie menor, sólo restringida al extremo sur del mismo (Manoiloff, 2008).

Desde el punto de vista fitogeográfico, el área se caracteriza por la presencia de bosques, sabanas, esteros y cañadas, distribución muy relacionada con la topografía, la composición y estructura del suelo y el tipo de escurrimiento hídrico. No existen ríos con caudales importantes, más bien arroyos, riachos o zanjones que se vinculan a subcuencas como las del Negro-Saladillo, Polvorín-Palometa y Tapenagá que, fuera de este ámbito, vierten al sistema fluvial exorreico Paraná-Plata (Bruniard, 1979; Manoiloff, 2008).

\subsection{El proceso de conformación territorial}

Hacia fines del siglo XIX, el gobierno nacional tenía claro que, de una vez por todas, el "desierto verde", como acostumbraban decir en Buenos Aires, debía ser arrebatado del dominio indígena con el fin de proceder a su organización político-administrativa y económica. Para su consecución, sin dudas, se llevaron a cabo férreas acciones militares y se promovió el poblamiento a medida que el ferrocarril se internaba en la foresta y las fábricas de tanino explotaban el quebracho colorado, proceso que se prolongó durante las primeras décadas del siglo siguiente.

A fines de 1910 las vías del ferrocarril Central Norte Argentino llegaban al Km 109 y, en los primeros meses del año siguiente, tocaban el Km 129, pero hubo que esperar un año para que los trenes comenzaran a cumplir su misión, llevando y trayendo productos a estas pequeñas poblaciones que incipientemente lograban sostenerse en proximidades de sendos desvíos. Las áreas boscosas circundantes fueron explotadas por pequeños obrajes, surgiendo así una población seminómada de hacheros que iban de un punto a otro buscando maderas para cortar, quedando población estable solamente en los alrededores de esos apeaderos ferroviarios. El único empresario forestal de fuste era, por entonces, el inmigrante italiano Vittorio Ghio (1865-1924), un obrajero a quien el Estado le comisionó producir los durmientes de quebracho colorado para el emplazamiento de las vías férreas; inicialmente instaló su campamento en la Colonia Novaró, a pocos km del actual Makallé y, luego, en proximidades del sitio que se llamaría Km 109. La capacidad productiva de su aserradero a vapor era de 1.200 durmientes diarios. Una vez cumplida su tarea y con el ferrocarril ya en funcionamiento, desarmó sus instalaciones y se radicó en Puerto Vicentini (Cuadra, 2007; García y Busiello, 1997).

En la evolución histórica del área de estudio, se puede observar que el actual departamento Presidencia de la Plaza fue parte de Guaycurú y Resistencia en las divisiones administrativas del Territorio 
Nacional del Chaco trazadas en 1885 y 1904; en la siguiente delimitación, realizada en 1915, perteneció casi enteramente a la jurisdicción de Martínez de Hoz. Sin embargo, el departamento 25 de Mayo fue parte de Solalinde, Guaycurú y áreas sin delimitar en la traza de 1885, agregándosele una parte de Resistencia en 1904; en 1915 quedó, casi por completo, dentro de la jurisdicción de Napalpí. La provincialización se llevó a cabo en 1951, a través de la ley nacional № 14.037, aunque la nueva división departamental se plasmó más tarde, en 1954 (ley provincial № 6) y, por lo tanto, Machagai quedó como cabecera del departamento 25 de Mayo, al tiempo que Presidencia de la Plaza pasó a cumplir idéntica función en el departamento homónimo.

La superficie ocupada entre ambas jurisdicciones suma $4.642 \mathrm{~km}^{2}$, correspondiéndole aproximadamente la mitad a cada uno, con la salvedad que Presidencia de la Plaza posee una topología más simétrica (abarcando $2.284 \mathrm{~km}^{2}$ ) y 25 de Mayo muestra un desarrollo más extendido hacia el norte y el sur, cubriendo una superficie de $2.358 \mathrm{~km}^{2}$ (INDEC, 1980).

La división catastral, en líneas generales, ha configurado una malla más apretada en 25 de Mayo, por la presencia de varias colonias agrícolas, en tanto, gran parte del departamento Presidencia de la Plaza (por sus rasgos hidro-topográficos) posee campos de gran extensión, con un perfil inicial claramente orientado a la ganadería extensiva y, en menor medida, a la agricultura. El número de parcelas en 1988, en el primer departamento, era de 1.919 con un tamaño medio de 122 hectáreas, al tiempo que en Presidencia de la Plaza se registraban 980 parcelas con un tamaño medio de 233 hectáreas. (Manoiloff, 2001).

Un aspecto en común es la existencia de numerosas colonias en el área, algunas de carácter agrícola y, otras, mixtas o pecuarias. Ya en 1911 fue creada la Colonia agrícola y pastoril Presidente Uriburu, dentro de la cual se emplazó el desvío Km 129. La estación Presidencia de la Plaza se implantó en las tierras fiscales de la colonia agrícola Cooperación, en tierras aún sin mensurar (Faure y Alcántara, 1918; Martínez, 2017).

Con el correr del tiempo, se constituyeron doce colonias en el área actualmente ocupada por el departamento 25 de Mayo (Presidente Uriburu, Blas Parera, La Tambora, Saavedra, Lamadrid, Arenales, Leandro Alem, Tres Palmas, El Aguará, El Guanaco, Pampa Bandera y, dentro de la Colonia Uriburu en 1944 se creó la Colonia Napalpí de 2.400 hectáreas en el frente norte de las vías del ferrocarril General Manuel Belgrano). En lo que es hoy el departamento Presidencia de la Plaza, se han conformado cuatro colonias: Hipólito Vieytes, Coronel Brandsen, La Dificultad y Pastoril (Lotes II, IV, V, VI y VIII); en cuanto a la Colonia agrícola Cooperación, debe decirse que tuvo un carácter meramente nominal, es decir, no se plasmó efectivamente en el territorio (Dellamea y Cuadra, 2015; Martínez, 2017).

Es importante resaltar que, a lo largo del proceso, surgieron en el interior de este espacio geográfico numerosos parajes o caseríos e, incluso, áreas popularmente llamadas colonias que aún subsisten o quedan algunos vestigios, como Santa Marta, Campo Varela, Gualtieri, La Lola, Los Blanquizales, El Paraisal y Martina (en 25 de Mayo) y, también, Guayaibí, Fortín Aguilar, Fortín Chajá, El Palmar, Cuatro Árboles, Santa Elena y El Curundú, entre otros (en Presidencia de la Plaza).

\subsection{Los caracteres demográficos y su evolución}

Los primeros pobladores no originarios que se internaron en las planicies boscosas del Chaco central pertenecían al ejército, que llevaba adelante la guerra contra la población nativa. Estos nuevos habitantes se acantonaban un tiempo en los fortines y, después, eran trasladados, aunque algunos de ellos se afincaron en el territorio, como es el caso del ex teniente Lionel Fitz Maurice, que se radicó en tierras que hoy pertenecen al departamento Presidencia de la Plaza (García y Busiello, 1997). Lo mismo sucedió con algunos obreros del ferrocarril, que se quedaron en la zona cuando las cuadrillas completaron su trabajo. En esas rudas condiciones iniciales construyeron sus viviendas, desmontaron, abrieron caminos, cultivaron, criaron ganado, formaron familias, edificaron escuelas y pusieron en marcha proyectos personales, comunitarios y sociales.

En 1909, don Pío González ocupó una amplia pradera en la zona conocida como "La Esperanza" hacia el norte de Machagai, aunque una incursión de originarios terminó abruptamente con el intento de promover la ganadería allí, perdiéndose unos 100 vacunos (Libro Histórico de la Escuela para Adultos № 3 de Machagai. Folio № 23).

Hacia 1910 los hermanos Rudaz se instalaron en los campos fiscales de Lote IV, luego Colonia Pastoril, provenientes de San Cristóbal, provincia de Santa Fe (Ruiz, 1967: 8). En 1911 se instaló en proximidades del Km 109 el inmigrante italiano Vittorio Ghio, quien comenzó la explotación de los extensos quebrachales (García y Busiello, 1997).

El fortín de Napalpí tuvo presencia de efectivos militares hasta 1911, cuando las autoridades 
nacionales consideraron que la permanencia de tropas en los fortines del centro del Chaco ya no era necesaria. En abril de 1911 arribó al Km 129, desde el norte santafesino, don José Suligoy para realizar agricultura y cría de ganado. Ese mismo año, en el marco de este proceso colonizador y en concordancia con la ley 5.559 del año 1908, de Fomento de los Territorios Nacionales, el Estado Nacional creó la Colonia Presidente Uriburu, para el desarrollo agrícola y pastoril, en lotes de 100 hectáreas que se les asignaban a familias, sobre todo españolas e italianas que fueron llegando al lugar hasta entrada la década de 1920. Asimismo, en octubre de 1911, fue creada la Reducción Nacional Aborigen Napalpí, con una superficie de 20.000 hectáreas y la finalidad de fomentar la instalación de las comunidades originarias dispersas, para impulsar su organización y evitar desentendimientos y conflictos con la población que iba ocupando las tierras del área. A fines de aquél año llegó el inmigrante Carlos Vecchietti, quien inicialmente se instaló en la recién creada Colonia Presidente Uriburu con el propósito de dedicarse a la agricultura (Dellamea y Cuadra, 2015).

La ocupación masiva de la zona con población no originaria, reconoce dos vertientes: una proveniente de Santa Fe y Corrientes, que se la denomina inmigración criolla y, otra, que procedía del extranjero o estaba constituida por la primera generación de inmigrantes extranjeros.

Es muy probable que las primeras casas ubicadas en las cercanías de los apeaderos ferroviarios de los Km 109 y 129 se hayan construido a partir de 1912, año en el que los trenes comenzaron a transitar, con paradas en estos puntos de la línea Barranqueras-Km 173. No obstante, el año 1921 resulta significativo para las dos localidades, dado que el acto administrativo-institucional de creación de las mismas, se produjo recién aquel año mediante el decreto nacional $\mathrm{N}^{\circ} 8.209$ del 11 de julio, firmado por el presidente de la Nación don Hipólito Yrigoyen. Por ese entonces, en el Km 109 (desde 1914 conocido como Estación Presidente de la Plaza, que luego derivó en Presidencia de la Plaza) habitaban 859 pobladores; en tanto, en el Km 129 (denominado Estación Machagai a partir de 1920), residían 193 personas. Con la implantación y la rápida propagación del cultivo algodonero, estas poblaciones experimentaron un explosivo crecimiento desencadenado a partir de mediados de la década de 1920, a tal punto que en 1934 Machagai superaba las 3.000 personas y Presidencia de la Plaza sumaba más de 4.000 habitantes. Este último mostró un incremento demográfico muy moderado entre los años treinta y sesenta y, en los setenta, redujo su población, es decir, no recepcionó a quienes emigraban del área rural. Muy diferente fue el caso de Machagai, que paulatinamente evidenció aumentos en el número de habitantes, máxime entre 1980 y 1991 a expensas del desarrollo de la industria forestal (Censos Territoriales de Población de 1920 y 1934. Censos Nacionales de Población de 1947-2010).

Tabla 1. Evolución demográfica de las localidades de Presidencia de la Plaza y Machagai.

\begin{tabular}{|c|c|c|}
\hline Años & $\begin{array}{c}\text { Población P. de } \\
\text { la Plaza }\end{array}$ & $\begin{array}{c}\text { Población } \\
\text { Machagai }\end{array}$ \\
\hline 1920 & 859 & 193 \\
\hline 1934 & 4.068 & 3.323 \\
\hline 1947 & 4.305 & 3.956 \\
\hline 1960 & 4.568 & 4.716 \\
\hline 1970 & 3.834 & 7.014 \\
\hline 1980 & 4.904 & 8.760 \\
\hline 1991 & 5.644 & 13.506 \\
\hline 2001 & 8.417 & 18.346 \\
\hline 2010 & 9.602 & 21.997 \\
\hline
\end{tabular}

Fuentes: Censos Territoriales de Población de 1920 y 1934. Censos Nacionales de Población de 1947-2010.

En cuanto a la población a nivel departamental, puede decirse que el gran crecimiento experimentado por Presidencia de la Plaza entre las décadas de 1920 y 1940, tendría un visible desgranamiento que se prolongaría hasta los años ochenta, situación indicativa de que no aparecieron paliativos después de la crisis algodonera y, recién desde los noventa en adelante se observa un crecimiento muy atenuado. Por su parte, la población de 25 de Mayo creció hasta 1960, se redujo en 1970 (debido a la problemática del algodón) y, posteriormente, evidenció un crecimiento moderado, mostrando signos de fortalecimiento en los años noventa, atribuibles al impulso industrial y demográfico de su ciudad cabecera. 
Tabla 2: Evolución de la población en los departamentos Presidencia de la Plaza y 25 de Mayo

\begin{tabular}{|c|c|c|}
\hline Años & $\begin{array}{c}\text { Población dpto. P. } \\
\text { de la Plaza }\end{array}$ & $\begin{array}{c}\text { Población dpto. 25 de } \\
\text { Mayo }\end{array}$ \\
\hline 1947 & 23.531 & 19.379 \\
\hline 1960 & 15.155 & 24.503 \\
\hline 1970 & 11.760 & 22.452 \\
\hline 1980 & 10.728 & 23.762 \\
\hline 1991 & 10.828 & 24.403 \\
\hline 2001 & 12.231 & 28.070 \\
\hline 2010 & 12.499 & 29.215 \\
\hline
\end{tabular}

Fuente: INDEC. Censos Nacionales de Población 1947-2010.

El campo, a través del avance del frente algodonero sobre tierras forestales, experimentó un vigoroso crecimiento demográfico entre los años treinta y sesenta. La población rural fue predominante durante gran parte del siglo XX; recién en la década de 1970 el departamento 25 de Mayo alcanzó un equilibrio entre la población urbana y rural, situación que también se daría en el departamento Presidencia de la Plaza a fines de los años ochenta. Por cierto, en 1960 la población rural constituía el 81\% en el primero y el $70 \%$ en el segundo, pero a raíz del colapso del cultivo textil se produjo la salida permanente e irrefrenable de esta población empobrecida (pequeños productores y braceros), al punto que en 1980 representaban el 39\% y el 54\% y, en 2010, solamente el 25\% y el 23\%, respectivamente. En 2010 el departamento 25 de Mayo contabilizó 29.215 habitantes (12,4 hab./ $\mathrm{km}^{2}$ ), de los cuales 21.997 vivían en Machagai, 1.272 en la localidad de Colonia Aborigen y 39 en Napalpí. A su vez, el departamento Presidencia de la Plaza registraba 12.499 habitantes (5,5 hab./ $\mathrm{km}^{2}$ ), de los que 9.602 residían en su ciudad cabecera (INDEC, 1970, 1980, 2010).

El arribo de europeos al área, tras la llegada del ferrocarril, estuvo representado mayormente por españoles e italianos y, excepcionalmente, franceses, alemanes u otras nacionalidades. Lo distintivo en este espacio es que, en la década de 1920, se produjo la instalación de una nutrida comunidad de montenegrinos en Machagai y en las colonias circundantes a ésta, razón por la cual se ha erigido en esta ciudad la única iglesia ortodoxa del Chaco. Entre los inmigrantes americanos, sobresalieron siempre los paraguayos en razón de su proximidad geográfica.

\subsection{Constitución de los centros urbanos}

Dados los inconvenientes insalvables que presentaba el terreno donde se levantaba el núcleo poblacional del Km 129 (bajo, pantanoso y propicio a inundaciones) y, en virtud de la aplicación del decreto nacional de 1921, se inició la mensura definitiva en un terreno ubicado aproximadamente a un km hacia el noroeste de dicho asentamiento, donde se observaba una marcada elevación. Hacia 1921, las constantes lluvias produjeron la inundación de varios pueblos del territorio chaqueño, entre ellos, Machagai. En reiteradas ocasiones, los habitantes del lugar reclamaron la mensura del nuevo pueblo en un sitio más alto y saludable, hasta que en febrero de 1925 el Poder Ejecutivo de la Nación dio a conocer las instrucciones especiales para posibilitar la relocalización del pueblo (Dirección General de Tierras de la Nación, División de Geodesia. Año 1926)

Le cupo al ingeniero José Schapira la tarea de diseñar el plano del pueblo nuevo de Machagai, aunque el primigenio caserío (surgido espontáneamente, sin mensura, un tanto desordenado y precario en torno al apeadero ferroviario) nunca dejó de tener población. El mismo profesional rediseñó el plano de Presidencia de la Plaza, que había sido elaborado por Delfín Gigena en 1925. En 1926, ambos planos estaban concluidos y, al año siguiente, fueron aprobados por las autoridades nacionales (Dirección General de Tierras de la Nación, División de Geodesia. Año 1926)

La traza de Presidencia de la Plaza consistió en un damero atravesado por cuatro avenidas diagonales que se inician en los terrenos del ferrocarril; el plano de Machagai también corresponde a un diseño de tipo damero con cuatro diagonales, pero las mismas se inician en su plaza central. En esta última localidad, el traslado de los habitantes a los nuevos terrenos, según se desprende de las entrevistas realizadas a antiguos pobladores, no se produjo en forma masiva, sino que fue un proceso individual y paulatino. Los factores que dificultaron una ágil reubicación fueron: por un lado, la resistencia de los mismos pobladores a abandonar el producto de sus esfuerzos y, por el otro, la permanencia de la estación del ferrocarril (factor dinamizador del movimiento económico) en el pueblo viejo hasta el año 1938 (Relatos de los antiguos 
pobladores G.G. y E.R.)

El 29 de octubre de 1928 fue creada la Comisión de Fomento de Presidencia de la Plaza y el 25 de abril de 1932, durante el mandato de Juan S. Mac Lean, se obtuvo del gobierno nacional la creación de la municipalidad de Presidencia de la Plaza (García y Busiello, 1997; Gutiérrez Viñuales, 2001). Actualmente es un municipio de $2^{\circ}$ categoría.

En Machagai, por resolución gubernamental del 7 de diciembre de 1928 se estableció la Comisión de Fomento (aunque la aprobación definitiva por parte del Poder Ejecutivo Nacional se produjo recién el 26 de marzo de 1929) y funcionó hasta noviembre de 1932, año en que fue creado el municipio, el cual desde 1993 posee una jerarquía de $1^{\underline{0}}$ categoría (A.H.P.CH. Documentos municipales. Consulta año 2016).

\subsection{La dinámica económica}

\subsubsection{La explotación forestal}

Al principio del proceso colonizador, la actividad forestal fue un denominador común en el entorno de ambos desvíos ferroviarios. En sus cercanías se extendían las playas donde se depositaban los rollos y rollizos que el tren transportaba a otros puntos del Chaco y del país. Hacheros, carreros, cargadores y changarines que venían de Corrientes, Santiago del Estero y de la República del Paraguay encontraban allí un modo de ganarse la vida. Algunos inmigrantes, o sus hijos, lograban instalar obrajes con peones criollos y originarios, para transportar las maderas en carros o cachapés tirados por yuntas de bueyes hasta las paradas ferroviarias (Relato de G.G., antiguo poblador).

Durante los años cuarenta, cincuenta y sesenta el número de aserraderos no era muy significativo en el centro este chaqueño, pero sí la explotación de rollizos y rollos que eran transportados exclusivamente por el ferrocarril al principio y, luego, por camiones hacia las fábricas de tanino localizadas cerca de Resistencia (Relato de A.L., antiguo poblador).

Un disparador muy importante para el crecimiento de la industria forestal en este espacio fue la puesta en funcionamiento, en 1978, de un emprendimiento estatal denominado MACHA (Maderas Chaqueñas Empresa del Estado Provincial), mediante el cual se logró duplicar la producción en Machagai. Esta empresa pasó por profundas crisis, hasta ser vendida a particulares que finalmente se declararon en quiebra. No obstante, esa circunstancia sería decisiva para el futuro de la actividad: las maquinarias se entregaron a los empleados que quedaron en paro como parte de las indemnizaciones, de modo que fueron ellos quienes le dieron el impulso necesario a la industrialización de la madera como actividad privada y, sus éxitos, rápidamente estimularon a otros emprendedores que se sumaron con nuevos aserraderos y carpinterías, generando una especie de boom foresto industrial en Machagai a fines de los ochenta, que se trasladó a Presidencia de la Plaza algunos años después de forma más atenuada. Actualmente, en esta última localidad funcionan unos sesenta y cinco establecimientos (aserraderos y/o carpinterías), mientras que en Machagai lo hacen alrededor de doscientos cincuenta (Relato de M.R., emprendedor maderero).

Para que se produjera este fenómeno, se conjugaron cuatro elementos que constituyeron el embrión del futuro crecimiento foresto industrial en el área: a) mano de obra con experiencia en la producción industrial, b) disponibilidad de maquinarias y equipamiento, c) existencia de un circuito de abastecimiento de materia prima y, d) presencia de demanda por parte de un enorme mercado a escala nacional (Dellamea y Cuadra, 2015).

Ya en la década de 1990, la industria maderera se presentaba como el puntal de la economía machagaiense, localidad que sería reconocida como la "capital del mueble de algarrobo" y, además, sede de la Feria Provincial de la Madera que se lleva a cabo anualmente.

Debe admitirse que la actividad foresto industrial en la zona vino a suplir, en parte, la falta de oferta laboral ocasionada por la severa crisis algodonera desatada a partir de la década de 1960 en el Chaco, situación que favoreció la expansión ganadera sobre tierras agrícolas y forestales. Como se sabe, la ganadería no es una actividad demandante de mano de obra numerosa. En consecuencia, gran parte de la población rural que abandonó su lugar en las décadas subsiguientes, trasladó las demandas laborales a los ámbitos urbanos.

El sistema forestal en el Chaco logró conformarse, adoptando la siguiente organización:

a. un espacio de oferta de materia prima: principalmente el noroeste provincial y, en menor medida, algunas áreas de ciertos departamentos, como San Lorenzo, Comandante Luis Fontana, Tapenagá y Libertador General San Martín. 
b. dos puntos de demanda de rollizos de quebracho colorado para la producción de tanino en el oriente chaqueño (La Escondida y Puerto Tirol).

c. un área de demanda de rollos en el centro de la provincia (Machagai, Presidencia de la Plaza y Quitilipi), donde se requiere fundamentalmente algarrobo y, en menor volumen, guayaibí, lapacho, urunday, tatané, guaraniná, quebracho blanco, quebracho colorado, guayacán y otras especies maderables para abastecer a las fábricas de muebles, aberturas, artículos rurales, rejillas, cajones y artesanías, entre otros productos.

d. aserraderos y carpinterías que, puntualmente o conformando pequeños parques industriales, se ubican en localidades en toda la provincia del Chaco, entre ellas Juan José Castelli, Tres Isletas, Villa Ángela, Presidencia Roque Sáenz Peña, General San Martín y Resistencia.

El éxito de la actividad foresto industrial en el centro este del Chaco se vincula con su situación geográfica favorable (centro de la provincia), su posición estratégica a nivel de las comunicaciones terrestres (sobre la Ruta Nacional № 16, que se enlaza con otras rutas provinciales y nacionales), su emplazamiento en un área gravitante desde los puntos de vista demográfico y productivo, a lo que debe sumarse la conformación de un empresariado creciente, aunque muy pocos de ellos con solvencia y capacidad financiera para realizar relevantes inversiones tecnológicas o de otro orden.

Este proceso, si bien en algunas instancias tuvo cierta participación estatal, se constituyó desde la iniciativa privada y, en cierto modo, funcionó por ensayo y error, apelando al sentido común de los emprendedores. Por esta razón, algunos eslabones de la cadena productiva aún funcionan anárquicamente, prevaleciendo los intereses individuales por sobre los beneficios generales, como ocurre a la hora de comercializar los productos. Esta praxis no cooperativa, ni asociativa, ha atentado contra la propia economía de los productores y contra los recursos naturales que representan la base de este sistema productivo: comercializar el producto lo más rústico posible, sin ensamblar, lijar o encerar (carentes de las terminaciones correspondientes) implica bajar los precios y perder el valor agregado, al tiempo que se obstruye la posibilidad de incorporar más mano de obra local y se reduce el circulante in situ, con lo cual se afecta la propia sustentabilidad del tejido social.

\subsection{Las actividades agropecuarias}

Con respecto al cultivo del algodón, el mismo empezó a implantarse en el área centro chaqueña en el transcurso de la segunda década del siglo XX. Datan de 1915 las primeras cosechas de algodón en proximidades de Machagai (Libro Histórico de la Escuela para Adultos № 3 de Machagai; Diario El Territorio, 15 de julio de 1981). Pero fue entre las décadas de 1920 y 1960 cuando tomó relevancia este cultivo, siendo el único sembradío que posibilitó el avance de la ocupación de gran parte del territorio chaqueño hasta los años sesenta. Hasta entonces, la expansión algodonera incorporó a nuevos productores y a una creciente mano de obra (cosecheros o braceros), muchos de ellos provenientes de una provincia vecina tradicionalmente expulsora de población, como Corrientes, pero también de otros puntos del Chaco y, en menor medida, de Santiago del Estero y de Paraguay (Bruniard, 1979; Maeder, 1997).

Al desatarse la crisis agrícola, una parte de los habitantes hizo abandono de las áreas rurales en forma inmediata, en tanto otros, trataron de sobrellevar la situación insertándose en algunas labores remanentes como peones de campos ganaderos, explotando maderas del bosque en tierras fiscales o privadas, cultivando algunas sementeras, criando animales, trabajando a destajo en labores rurales ocasionales (limpieza de alambrados, marcación y señalada de vacunos, colocación de infraestructura, etc.) o desarrollando determinadas actividades por cuenta propia (Relato de J.V., antiguo poblador rural).

En los años ochenta el éxodo rural se intensificó inexorablemente hasta el presente. Entre sus causas, aparte de la problemática algodonera, deben mencionarse: la escasa mano de obra demandada por las actividades ganaderas y la explotación forestal y, por otro lado, las ventajas ofrecidas por el medio urbano en cuanto a trabajo, educación, salud y diferentes servicios, que abrían la alternativa de una calidad de vida superior en términos generales.

El área rural, tras la crisis de la actividad agrícola, vio expandir la ganadería bovina con modalidad extensiva y, luego de los años ochenta, las cabeceras departamentales arraigaron a la industria forestal. La ganadería tiene en los pastizales el principal recurso forrajero, complementado, en algunos casos, por pasturas y rastrojos de cultivos. La producción tiene como destino esencial la invernada (preferentemente en la llanura pampeana o en los feedlots localizados en la propia provincia o región) y la faena en frigoríficos de la zona. 
Como ha dicho Carl Sauer (1925: 22): “...el paisaje cultural es creado por un grupo cultural a partir de un paisaje natural. La cultura es el agente, el área natural es el medio y el paisaje cultural es el resultado...”.

Tal apreciación se ha observado en el espacio estudiado, donde los descendientes de inmigrantes, cargados de una lógica productiva de maximización de ganancias, al llegar a la zona tomaron la mayor cantidad de tierras que les estaba permitido, en tanto los correntinos, con una lógica asociada al buen vivir, sólo tomaron la superficie que iban a trabajar, que les permitía reproducirse, pero sin ánimo de acumulación (Relato de J.V., antiguo poblador rural).

Es interesante observar que, en el área de Presidencia de la Plaza, los ganaderos provenientes de Santa Fe ocuparon con sus animales las tierras que habían sido despobladas de habitantes originarios por la acción militar previa (proceso de desterritorialización). Pero, con el paso del tiempo y el advenimiento de la agricultura, se dio lugar a una nueva configuración espacial, ubicándose los agricultores al norte de las vías del ferrocarril (terrenos predominantemente más altos), mientras que los ganaderos lo hicieron al sur de la misma, en superficies más bajas, lo que representa una división empírica del territorio en una época en que no existían servicios de asistencia técnica. En 25 de Mayo este proceso también se dio, pero más atenuado (mayormente en los extremos norte y sur), dado que gran parte de sus tierras estaban orientadas a la agricultura o a actividades mixtas.

La ganadería se fue posicionando favorablemente con el correr de los años, tanto cuantitativa, como cualitativamente, evidenciándose un significativo mejoramiento en los planteles vacunos del área, tanto en razas como en manejo, condiciones sanitarias y alimentación.

En el departamento Presidencia de la Plaza las explotaciones agropecuarias (EAPs) disminuyeron visiblemente entre 1988 y 2002, período en el cual la superficie de EAPs se redujo levemente (8,3\%), observándose un leve cambio de tendencia en 2008, de la mano de un aumento de la superficie involucrada del 15,3\%. Este comportamiento evidencia una marcada concentración y polarización de las actividades agropecuarias en esa jurisdicción. Sin embargo, en 25 de Mayo, el número de EAPs mostró un crecimiento significativo entre 1988 y 2002 y la superficie de las mismas aumentó escuetamente (3,1\%), aunque para el año 2008 la cantidad de EAPs experimentó una disminución e igualmente la superficie abarcada por ellas (2,7\%) (INDEC, 1988, 2002 y 2008).

Tabla 3: Evolución de las EAPs en ambos departamentos.

\begin{tabular}{|c|c|c|}
\hline Años & P. de la Plaza & 25 de Mayo \\
\hline 1988 & 552 & 736 \\
\hline 2002 & 382 & 910 \\
\hline 2008 & 397 & 851 \\
\hline
\end{tabular}

Fuente: INDEC. Censos Agropecuarios. Años 1988,2002 y 2008.

Es importante resaltar que la implantación de la soja en el centro este chaqueño no tuvo el éxito que se ha observado en el centro suroeste y oeste de la provincia. Sucede que una empresa del agro, para incorporarse a la zona, requería adquirir una importante cantidad de superficie, al menos unas 2.000 hectáreas. Ello no fue factible, dado que la reconfiguración de los productores en este ámbito se dio a través de la mecánica de adquisición de tierras por parte de propietarios vecinos con cierta capacidad de compra, práctica que funcionó como barrera para las grandes empresas agropecuarias, frenando así su ingreso masivo en el área (situación observada principalmente en Presidencia de la Plaza). Esta percepción concuerda con lo observado por Paruelo y Oesterheld, quienes demostraron que “...el aumento en el área sembrada con soja fue mayor en los departamentos que tuvieron menor proporción de la superficie del departamento ocupada por pequeños productores (menos de 100 has)..." (Paruelo y Oesterheld, 2004: 47).

La distribución parcelaria impidió el ingreso de los actores extra regionales, pero el modo de producción y la estructura del sector se modificaron sustancialmente en comparación con la etapa de predominio del algodón (1930-1960). La venta de las pequeñas unidades productivas a ciertos actores locales, fue generando -en cierta medida- un proceso de concentración de la tierra. Los que no vendieron y tenían muy poca superficie de terreno, la alquilaron a un vecino innovador y exitoso dispuesto a invertir en el campo, apostando a la ganadería y obteniendo mejores rindes y ganancias, en comparación con quienes optaron por seguir cultivando el algodón (Sacchi y Martínez, 2016).

En 25 de Mayo, el incremento de las EAPs estuvo más relacionado con la fragmentación de la tierra por razones hereditarias y, en menor medida, por la anexión de nuevas tierras a la producción pecuaria. Este departamento pasó de tener una cifra cercana a las 30.000 hectáreas sembradas en el esplendor algodonero, a menos de 3.000 hectáreas en la actualidad. En Presidencia de la Plaza se llegaron a cultivar 
18.000 hectáreas en el auge del "oro blanco" y, en el presente, la cifra sólo alcanza 400 hectáreas. Este fenómeno se tradujo en expulsión de población rural y liberó amplias superficies a la actividad pecuaria.

La ganadería vacuna extensiva, erigida en la actividad económica dominante en el medio rural, experimentó un crecimiento importante en las dos jurisdicciones desde mediados de los cincuenta al presente, sobre todo en 25 de Mayo, que en los noventa logró duplicar sus existencias ganaderas. En la actualidad, entre ambos departamentos, representan el 9\% del stock bovino de la provincia del Chaco.

Tabla 4. Evolución del stock bovino en ambos departamentos.

\begin{tabular}{|c|c|c|}
\hline Años & P. de la Plaza & 25 de Mayo \\
\hline 1955 & 41.456 & 49.898 \\
\hline 1998 & 79.151 & 112.863 \\
\hline 2008 & 107.082 & 132.767 \\
\hline 2018 & 98.450 & 137.976 \\
\hline
\end{tabular}

Fuentes: 1ํㅡㄹo Provincial Agropecuario del Chaco. Año 1955. SENASA. Años 1998-2018.

\section{Discusión de los resultados}

Es evidente que por razones de contigüidad y continuidad, el espacio geográfico abarcado en la actualidad por los departamentos Presidencia de la Plaza y 25 de Mayo, presenta muchos aspectos naturales y humanos en común. Gran parte de los caracteres físicos y biológicos tienen homogeneidad o, al menos, suficiente similitud para agruparlos en un mismo ambiente. Asimismo, los pueblos originarios que los habitaban, el proceso militar previo a la colonización, la instalación de ganaderos procedentes del norte santafesino, la incidencia del ferrocarril en la formación de los asentamientos, la evolución político-administrativa y la dinámica económica, poseen más denominadores comunes que diferencias. No obstante, se puede observar que, durante gran parte del proceso geohistórico, el área de 25 de Mayo ha mostrado una dinámica mayor, sobre todo desde el punto de vista demográfico, incorporando montos superiores de población tanto en el medio urbano como rural. De hecho, el número de colonias establecidas en este ámbito cuadruplica a las emplazadas en Presidencia de la Plaza.

El movimiento económico también ha mostrado mayor relevancia en 25 de Mayo y, ello, se aprecia analizando distintos indicadores, tales como: el número de EAPs, de hectáreas sembradas, radicación de desmotadoras en la etapa algodonera, cabezas de ganado vacuno y número de establecimientos foresto industriales. La condiciones topográficas más proclives al anegamiento, en gran parte del espacio placeño, posiblemente actuó como un factor limitante en el logro de un mayor impulso demográfico y económico a lo largo del tiempo.

El aspecto cultural también ha tenido una gran incidencia en la organización del territorio y, producto de ello, se conformó la idiosincrasia de estas poblaciones. Entre los factores actuantes no pueden dejarse de mencionar los siguientes:

a. 25 de Mayo contiene al grueso de la población originaria, pues desde 1911, al conformarse la Reducción de Indios Napalpí, luego denominada Colonia Aborigen Chaco, estas comunidades fueron desplazadas hasta ese lugar. Por esa razón, Presidencia de la Plaza alberga a muy pocos habitantes originarios, en tanto 25 de Mayo posee población qom en Machagai, en el pueblo de Colonia Aborigen Chaco, en el ámbito rural de dicha colonia y, también, fuera de ella.

b. En las primeras décadas del siglo XX, 25 de Mayo recibió un significativo flujo de inmigrantes españoles, italianos y yugoslavos (montenegrinos), mientras que en Presidencia de la Plaza arribaron predominantemente españoles y, en menor número, italianos.

c. En ambos sitios se instalaron criollos correntinos y paraguayos en la época del auge algodonero, cuyos descendientes mantienen rasgos idiomáticos (guaraní), costumbres, música y danza (chamamé) hasta el presente.

d. También dentro de lo cultural, se aprecia como rasgo distintivo de 25 de Mayo, la presencia de una gran cantidad de iglesias y congregaciones evangélicas y, además, una iglesia católica apostólica ortodoxa que reúne mayormente a los descendientes de inmigrantes montenegrinos.

\section{Conclusiones}

Se ha podido constatar que los caracteres del medio natural y la marcha del proceso histórico 
muestran muchos elementos en común en todo el espacio geográfico estudiado. Igualmente, fue posible comprobar la presencia de una fuerte interrelación y retroalimentación, no sólo entre las ciudades cabeceras, sino también en el medio rural en esta parte del centro este chaqueño.

De hecho, ambas poblaciones, Presidencia de la Plaza y Machagai (y sus entornos) son hijas del ferrocarril, sustentadas inicialmente por la explotación forestal y, luego, volcadas al cultivo del algodón. Al volverse inviable este cultivo, estos ámbitos ampliaron y fortalecieron la actividad ganadera y, a partir de los últimos años del siglo XX, desarrollaron la industria forestal. En la actualidad, ambos departamentos poseen medios rurales con un perfil netamente pecuario, al tiempo que sus cabeceras urbanas se hallan orientadas a la actividad foresto industrial.

A través de los trabajos in situ y de numerosas entrevistas cuyos interlocutores fueron mayormente antiguos pobladores y emprendedores de la zona, se ha podido reconocer la existencia de fuertes relaciones parentales en el área y, asimismo, la asociación y complementación de prácticas productivas y comerciales. Además, se evidenció la presencia de un importante flujo compuesto por estudiantes, empleados, docentes y otros profesionales que, cotidianamente o con cierta frecuencia, se desplazan de Presidencia de la Plaza a Machagai y viceversa, por razones de capacitación y trabajo, fundamentalmente. Dicho flujo también se replica en el ámbito rural, donde la intercomunicación obedece, sobre todo, a razones de índole social y económica.

En las últimas décadas, el territorio analizado logró reacomodarse, tras la abrupta crisis agrícola de fines de los años sesenta y setenta, a través de algunas estrategias productivas:

a. fortalecimiento de la ganadería bovina como actividad generalizada, incluso en áreas que anteriormente fueron algodoneras y forestales.

b. desarrollo de una agricultura muy acotada (en comparación con las superficies sembradas durante las décadas de 1930 a 1960), orientada a la dieta animal (producción de forrajes y granos) $\mathrm{y}$, en menor medida, a otros cultivos en áreas tradicionalmente algodoneras o en superficies desmontadas.

c. concentración de establecimientos foresto industriales (especialmente fábricas de muebles) en las ciudades de Machagai y Presidencia de la Plaza, para abastecer esencialmente al mercado provincial y nacional.

d. afianzamiento del comercio y de los servicios para dar cobertura a las demandas de la población local, del entorno rural, de pueblos vecinos y de actores que llegan desde otros puntos de la región y del país (vinculados con la actividad foresto industrial, con labores conexas y con la dinámica generada por la propia complejidad de los servicios: educación, salud, seguridad, finanzas u otras profesiones y empleos).

No obstante las semejanzas señaladas, se aprecian rasgos particulares en uno y otro espacio: Machagai es una localidad más dimensionada desde el punto de vista demográfico, comercial, industrial, edilicio y urbanístico en general, en tanto Presidencia de la Plaza expone rasgos más pueblerinos, situación que se refleja en aspectos como la menor circulación vial, la simplicidad de su arquitectura y en las costumbres y prácticas cotidianas de su gente. En materia de sucesos culturales, Machagai también ha logrado un mejor posicionamiento (festividades, congresos, exposiciones y ferias). Lo mismo ocurre al considerar la cantidad de establecimientos educativos primarios y secundarios y el número de carreras terciarias que ofrecen sus institutos de formación superior.

En el plano económico, el departamento 25 de Mayo posee una densidad y un stock ganadero más elevado que Presidencia de la Plaza y, vinculado a ello, la población rural presenta un monto y una densidad superior. Por su parte, la industria maderera tiene un peso mayor en Machagai, tomando en cuenta el número de aserraderos, carpinterías, emprendedores forestales, volumen de madera procesada y diversidad de su producción.

\section{Referencias bibliográficas}

A.H.P.CH. Documentos municipales. Fichas de Pueblos. Caja N 1 y 2. Resistencia, Chaco.

A.H.P.CH. Libros de Registro, № 445 a 455. Resistencia, Chaco.

Beck, H. (1994). Relaciones entre blancos e indios en los Territorios Nacionales de Chaco y Formosa. 1885-1950. Cuadernos de Geohistoria Regional, № 29. Instituto de Investigaciones Geohistóricas. CONICET. Resistencia, Chaco. 
Blanco, J. (2007). Espacio y territorio: elementos teórico-conceptuales implicados en el análisis geográfico. En: Fernández Caso, M. V. y Gurevich, R. (Coordinadoras). Geografía. Nuevos temas, nuevas preguntas. Un temario para su enseñanza. Ed. Biblos. Claves para la Formación Docente. Buenos Aires, Argentina.

Bozzano, H. (2009). Territorios posibles. Procesos, lugares y actores. Ed. Lumiere. Buenos Aires, Argentina.

Bruniard, E. D. (1979). El Gran Chaco Argentino. Revista Geográfica № 4. Instituto de Geografía. UNNE. Resistencia, Chaco.

Cuadra, D. E. (2007). Makallé. Lucha y existencia de un pueblo chaqueño. Moglia S.R.L. Corrientes, Argentina.

Cuadra, D. E. y Martínez, G. R. (2017). Documentos primarios. Resultados de trabajos de campo: observaciones y entrevistas a antiguos pobladores y emprendedores (período 2014-2017). Inéditos. Machagai - Presidencia de la Plaza, Chaco.

Chayanov, A. V. (1925) 1985. La organización de la unidad económica campesina. Nueva Visión. Buenos Aires, Argentina.

Daus, F.(1961). ¿Qué es la Geografía?. Ed. Columba. Buenos Aires, Argentina.

Dellamea, S. G., y Cuadra, D. E. (2015). Machagai y colonias vecinas. Geografía, historia, política, economía, sociedad y cultura del Departamento 25 de Mayo, en la Provincia del Chaco. ConTexto. Resistencia, Chaco.

Diario El Territorio (1981). Machagai. Publicación de fecha 15 de julio, pp. 17. Resistencia Chaco.

Dirección General de Tierras. Geodesia (1926). Archivo de Mensuras. Ing. José Schapira. Aprobación del Decreto del P.E. 4 -VII, Libreta N³5/3, pp. 3-7. Resistencia, Chaco.

Dollfus, O. (1976). El espacio geográfico. Ed. Oikos Tau. Barcelona, España.

Faure, E. H. y Alcántara, M. (1918). Mapa de la Gobernaciones de Formosa y Chaco y parte de la Provincia de Salta. Buenos Aires, Argentina.

Foucoult, M. (2004).Seguridad, territorio, población. Curso en el Collège de France 1978-1999. Fondo de Cultura Económica. Colección Sociología. Buenos Aires, Argentina.

García, G. M. y Busiello, O. C. (1997). Presidencia de la Plaza. Sus Orígenes 1910 - 1940. Concepción del Uruguay, Entre Ríos.

Gutiérrez Viñuales, R. (2001). La provincialización del Chaco. El histórico proceso de un anhelo (18841951). (F. CEDODAL, Ed.). CABA, Argentina.

Haesbaert, R. (2004). O mito da desterritorializaçao: do "fim dos territórios" á multiterritorialidade. Bertrand. Río de Janeiro, Brasil.

INDEC. Censos Nacionales de Población. Años 1970, 1980, 1991, 2001, 2010. Buenos Aires, República Argentina.

INDEC. Censos Nacionales Agropecuarios. Años 1988, 2002 y 2008. Resultados generales. Buenos Aires, República Argentina.

LANDSAT. Imágenes satelitales TM. Cobertura: centro de la provincia del Chaco. Argentina. Escala 1:500.000. Buenos Aires, Argentina.

Libro Histórico de la Escuela para Adultos № 3 de Machagai. Folios 1-25.

Maeder, E. J. (1997). Historia del Chaco. Ed. Plus Ultra. Buenos Aires, Argentina.

Manoiloff, R. O. (2001). El cultivo del algodón en el Chaco entre 1950 y nuestros días. La etapa de crisis. Meana Impresores. Resistencia, Chaco.

Manoiloff, R. O. (2008). Atlas Geográfico de la Provincia del Chaco. Tomo I: El medio natural. Revista Geográfica № 14. Instituto de Geografía, UNNE. Resistencia, Chaco.

Martínez, G. R. (2017). La dinámica socio-territorial en el centro este chaqueño desde fines del siglo XIX hasta principios del siglo siglo XXI. Tesis doctoral. Inédita. UNNE. Presidencia de la Plaza, Chaco.

Massey, D. (1994). Space, Place, and Gender. University Minnesota Press. USA.

Ministerio de Agroindustria. Provincia del Chaco. Estimaciones agrícolas. Provincia del Chaco. Disponible en: https://datos.agroindustria.gob.ar/dataset?tags=Chaco 
Miranda, G. (1961).Tres ciclos chaqueños: (crónica histórica regional). Editorial Norte Argentino. Resistencia, Chaco.

Paruelo,J. M., y Oesterheld, M. (2004). Patrones espaciales y temporales de la expansión de Soja en Argentina. Relación con factores socio-económicos y ambientales. Facultad de Agronomía. Universidad de Buenos Aires, Laboratorio de Análisis Regional y Teledetección. Buenos Aires.

Pickenhayn, J. A. (1994). Epistemología y Geografía. Ed. Plus Ultra. Buenos Aires, Argentina.

Plans, P. et al. (1984). Introducción a la Geografía General. Ed. EUNSA. Pamplona, España.

Provincia del Chaco (1955). $1^{\circ}$ Censo Provincial Agropecuario del Chaco. Resistencia, Chaco.

República Argentina (1920). Censo General de los Territorios Nacionales. Tomo I: La Pampa, Misiones, Los Andes, Formosa y Chaco. Buenos Aires, Argentina.

Ruiz, P. A. (1967). Algunas referencias sobre Presidencia de la Plaza y la Escuela Nacional № 58. Mimeo. Escuela № 58, Presidencia de la Plaza, Chaco.

Sacchi, P., y Martínez, G. R. (2016). Territorios rurales del Centro de la Provincia del Chaco. Departamento Comandante Fernández. Periodo: 1988-2008. Pre-ALASRU. Santiago del Estero.

Sauer, C. O. (1925). La morfología del paisaje. University of California. Publications in Geography.Vol. 2, № 2, pp. 19-53.

SENASA. Datos de Vacunación anual. Existencias de ganado bovino por departamento. Provincia del Chaco. Años 1998-2018.

Tuan, Y. F. (2007). Topofilia. Ed. Melusina S.L. España.

Vasilachis de Gialdino, I. (2011). De la ocupación al diálogo. Nuevas formas de conocer, de representar, de incluir. Discurso \& Sociedad, Vol. 5, № 1, pp. 132-159. España. 